Original Research Paper

\title{
Epidemiological Characteristic of Animal Bite and Direct Economic Burden of Rabies Vaccination in the Southern of Iran
}

\author{
${ }^{1}$ Vahid Rahmanian, ${ }^{1}$ Heshmatollah Shakeri, ${ }^{1}$ Abdolreza Sotoodeh Jahromi, \\ ${ }^{1}$ Masihollah Shakeri, ${ }^{2}$ Hekmatollah Khoubfekr and ${ }^{3}$ Iman Hatami \\ ${ }^{I}$ Zoonoses Research Center, Jahrom University of Medical Sciences, Jahrom, Iran \\ ${ }^{2}$ Iranshahr Health Services, Iranshahr University of Medical Sciences, Iranshahr, Iran \\ ${ }^{3}$ Larestan Health Center, Larestan University of Medical Sciences, Larestan, Iran
}

\author{
Article history \\ Received: 02-05-2020 \\ Revised: 05-10-2020 \\ Accepted: 06-10-2020 \\ Corresponding Author: \\ Masihollah Shakeri \\ Zoonoses Research Center, \\ Jahrom University of Medical \\ Sciences, Jahrom, Iran \\ Email: shakeri13@gmail.com
}

\begin{abstract}
The ever-increasing cases of animal bites caused by rabies, livestock losses, as well as economic damages are of utmost importance in developing countries. This study was conducted to determine the epidemiology and the direct economic burden of rabies vaccination in southern Iran in 2018. In this study, 375 cases of animal bites which were recorded in Rabies Treatment Centers of Larestan County, Iran were entered into the study by census method. The data were collected from the registered office profile of people who had referred to these centers. The variables examined included victims' demographic characteristics, bite specifications, spatial and temporal patterns, victims' clinical dimensions and vaccination costs. Of 375 registered cases, $83.7 \%$ of the cases were male and there was no statistically significant difference between the mean age of males $(30.82 \pm 17.31)$ and females $(30.49 \pm 18.79)(\mathrm{P}=0.895)$. As well, $58.7 \%$ of the victims were residing in urban areas and farmers $(25.6 \%)$ and students $(23.9 \%)$ were the most frequent occupational groups suffering from animal bites \%) ( $\mathrm{p}<0.001)$. The most cases of the bites i.e., $68 \%$ had been also produced by dogs and $64 \%$ of them were from the owned biting animals. As well, direct costs were estimated US\$ 9373 for vaccine, US\$ 24115 for rabies RIG and the US\$33488 cumulative economic burden in the studied period. In conclusion, it is found that the major cases of animal bites in Larestan County had been caused by dogs and owned biting animals which could impose a heavy burden on Iran's economy.
\end{abstract}

Keywords: Epidemiology, Animal Bites, Rabies, Economic Burden, Larestan

\section{Introduction}

Rabies is known as one of the most dangerous viral zoonotic diseases that can infect all mammals (Tiembré et al., 2018). Despite being preventable and given the existence of safe and effective vaccines, rabies has still remained a major health problem in numerous countries across the world (Kasem et al., 2019; Banyard et al., 2018). Considering the incidence rate of rabies in the world, Iran is one of the countries with a history of rabies occurring both in wildlife and domestic animals. The given disease is still recognized as one of the health-related and economic problems and almost infection cases with rabies are observed more or less in all provinces in Iran (Abedi et al., 2019; Hamta et al., 2019).

According to Pasteur Institute of Iran, in the northern provinces of Iran foxes, jackals and dogs are carrying rabies. In the northwest and western provinces, wolves, the natural reservoir of rabies virus is also carriers. In the most cities and villages, urban rabies is common among stray dogs and cats. Therefore, in Iran, surveillance system carries out primary prevention (Post-Exposure Treatment-PET) for total animal bite cases, regardless of the animal's carrier status of rabies virus for prevention of rabies (Abedi et al., 2019; Gholami et al., 2017).

Post-exposure treatment-PET in Iran is such that the rabies vaccine is injected based on the WHO protocol, 
which has been prepared with regard to the severity of the injury and the amount of contamination. Based on this, the people referred to include three groups: Group A: Calling or feeding animals, losing healthy skin that does not require vaccine and RIG. Group B: Include teeth of naked skin, small scabs without bleeding, who should receive a vaccine. Group C: Include deep wounds and exposure to bats that should receive vaccine and RIG. In Iran, the Essen Regimen is used for immunization, which consists of five injections of vaccine on days $0,3,7,14$ and 28 , respectively. In cases where the animal, the dog and the cat are the owner and survive 10 days after the bite event, this means that the dog or cat is not carrying rabies at the time of the event and the patient does not receive the vaccine 14 and 28 (Abedi et al., 2019).

Increased incidence rate of animal bites can also result in rising economic costs for the care and treatment of victims including the costs of vaccines and Rabies Immunoglobulin (RIG) in a way that its global costs have been estimated by one billion US dollars annually (Wangdi and Ward, 2012; Anyiam et al., 2017).

Wangdi and Ward (2012) in Bhutan showed that the average direct medical cost of human post-exposure treatment was US\$ 35.65 per 5-dose Essen regimen per patient if rabies vaccine is used only. The cost would increase to US\$ 55.13 and US\$ 433.41 per patient when one dose of either Equine Rabies Immunoglobulin (ERIG) or human rabies immunoglobulin.

The PET costs and those for canine rabies prevention and control programs are similarly known as the most significant determinants of social costs of rabies in endemic countries. In addition, costs of PET in countries where in their healthcare systems are based on out-ofpocket payments and the major costs are directly payable by the public are extremely burdensome (Shwiff et al., 2018; Le et al., 2018).

The economic costs of animal bites can be divided into direct costs (vaccine, Rabies Immunoglobulin- RIG, syringe, disinfectants, staff salaries, etc.) and indirect costs (costs of transports by patients to receive PET and costs of losing income during visits) that can have a significant impact on disease control (Wangdi and Ward, 2012). In addition to the financial costs of animal bites prevention and treatment; socio-psychological consequences of bites and the remaining scars can also greatly affect the life of individuals and their families (Babazadeh et al., 2016; Mbilo et al., 2019).

Therefore, obtaining accurate information about the economic burden of animal bites can help decisionmakers in different countries in terms of prioritization and estimation of the problem severity, cost-benefit achieved compared to other methods of reducing incidence rates of animal bites and allocation of resources, as well as fight against the disease. Accordingly, the purpose of this study was to determine the epidemiology and the direct economic burden of rabies vaccination in Larestan in 2018.

\section{Methodologies}

In this study, 375 cases of animal bite in a one-year period between 21st March 2018 to 20th March 2019 longitudinally in Larestan County located in the south Fars province, Iran were entered in to the study by a census method.

The animal bite clinics and treatment centers in this County had five units for the prevention of rabies, which provided health care and treatment services for all victims of animal bites. The data were collected through the information of the registered profiles of individuals who had referred to the Rabies Center of Larestan County. Normally, these forms included variables of age, gender, living place, type of biting animal, occupation, number of injury, bite site (hand, leg, body, face and head or neck), bite date, the number of receiving anti rabies vaccination and rabies immunoglobulin and tetanus vaccine. Data on the bitten subjects were extracted from rabies Surveillance System of the Health Deputy of Larestan University of Medical Sciences.

\section{Study Site}

In the geographical place where this study is focused, people commonly did not keep pet dogs with themselves at the home like the western culture, but the dogs were usually used as guard at the house yard or with the sheep herds. No national rabies vaccination program was run in Iran for dogs and other pets. In urban regions, most people did not keep pet dogs and the most dogs in these regions were stray dogs.

\section{Animal Bitten Participants}

The participants of this study included individual who referred to animal bite clinics and treatment centers due to fear of contracting rabies and/or other diseases from animal bites. All cases of animal bites in all age and sex groups referred to animal bite clinics and treatment centers in the study period were included in the study.

\section{Statistical Analysis}

The data were analyzed by Statistical Package for the Social Sciences Version 17.0 (SPSS Inc., Chicago, IL, USA). Descriptive statistics (frequency and relative frequency), chi-square test and independent samples ttest at the significance level of 0.05 were used to analyze the collected data.

\section{Results and Discussion}

In total, 375 bitten subjects with a mean age of $(30.76 \pm 17.53)$ were registered and there was no 
statistically significant difference between the mean age of males $(30.82 \pm 17.31)$ and females $(30.49 \pm 18.79)(\mathrm{P}=$ $0.895)$. The bite rates in males were $83.7 \%$ among the various occupation, formers had at the highest bite rate (25.6\%), followed by the students (24\%) and the workers $(14.67 \%)$. The most involved age group for the males and the females were 40-49 years old. The place of residence of 220 cases $(58.7 \%)$ were urban regions. In terms of the place of bites, 203 cases $(54.1 \%)$ occurred in urban regions. In this year, most of the cases of animal bites were in October $(10.9 \%)$, December $(10.4 \%)$ and January (9.9\%), respectively (Fig. 1).
Most bites happened by dogs (68\%), cats (26.9\%) and horses $(1.3 \%)$, respectively. In addition, only $34 \%$ of the animals were stray and $64 \%$ of them were owners (Table 1).

The upper extremities were the most frequent bite site (54.7\%) followed by the lower extremities, trunk and head-face, respectively (Fig. 2).

In terms of the number of the wound, $214(57.1 \%)$ of subjects had one lesions, 114 (30.4\%) two and 47(12.5\%) 3 and more had lesions. In term of Time (o'clock) animal bites $29.06 \%$ happened in early morning (between 5 to 10 $\mathrm{am}$ ) and $27.2 \%$ at midday (between 11am to 3:00 pm).

Table 1: Frequency distribution of animal bites cases by biter animals in Larestan county, Fars province, southern Iran

\begin{tabular}{|c|c|c|c|c|}
\hline \multicolumn{2}{|l|}{ Variables } & \multirow{2}{*}{$\begin{array}{l}\text { Frequency } \\
314\end{array}$} & \multirow{2}{*}{$\begin{array}{l}\text { Percentage } \\
83.70\end{array}$} & \multirow[t]{2}{*}{ p-value* } \\
\hline Gender & Male & & & \\
\hline & Female & 61 & 16.30 & $<0.001$ \\
\hline \multirow{7}{*}{ Occupation } & Formers & 96 & 25.60 & \\
\hline & Students & 90 & 24.00 & $<0.001$ \\
\hline & Workers & 55 & 14.67 & \\
\hline & Private businessmen & 48 & 12.80 & \\
\hline & Housewives & 37 & 9.87 & \\
\hline & Public officers & 18 & 4.80 & \\
\hline & Others & 31 & 8.27 & \\
\hline \multirow[t]{6}{*}{ Age } & $<4$ & 8 & 2.10 & \\
\hline & 9-May & 27 & 7.20 & $<0.001$ \\
\hline & 19-Oct & 74 & 19.70 & \\
\hline & $20-29$ & 84 & 22.40 & \\
\hline & $30-39$ & 86 & 22.90 & \\
\hline & $40-49$ & 96 & 25.60 & \\
\hline \multirow[t]{2}{*}{ Place of residence } & Urban & 220 & 53.80 & \\
\hline & Rural & 155 & 41.30 & 0.001 \\
\hline \multirow[t]{2}{*}{ Place of bites } & Urban & 203 & 54.10 & \\
\hline & Rural & 172 & 45.90 & 0.109 \\
\hline \multirow[t]{4}{*}{ Season } & Spring & 90 & 24.00 & \\
\hline & Summer & 76 & 20.30 & 0.132 \\
\hline & Autumn & 102 & 27.20 & \\
\hline & Winter & 107 & 28.50 & \\
\hline \multirow[t]{11}{*}{ Animal species } & Dog & 255 & 68.00 & \\
\hline & Cat & 101 & 26.90 & $<0.001$ \\
\hline & Hours & 5 & 1.30 & \\
\hline & Monkey (pet) & 2 & 0.50 & \\
\hline & Sheep & 1 & 0.30 & \\
\hline & Donkey & 1 & 0.30 & \\
\hline & Hamster & 3 & 0.80 & \\
\hline & Wild pigs & 3 & 0.80 & \\
\hline & Fox & 2 & 0.50 & \\
\hline & Wolf & 1 & 0.30 & \\
\hline & Hedgehog & 1 & 0.30 & \\
\hline
\end{tabular}

*Chi- Square test

Table 2: Costs of rabies vaccination and RIG therapy for animal bite victims referred to animal bite clinics and treatment centers in Larestan county, Fars province, south of Iran (2018)

\begin{tabular}{llllr}
\hline $\begin{array}{l}\text { Number of vaccines } \\
\text { and rabies RIG }\end{array}$ & $\begin{array}{l}\text { Number of } \\
\text { animal bite victims }\end{array}$ & $\begin{array}{l}\text { Frequency vial of lyophilized } \\
\text { vaccine and rabies RIG }\end{array}$ & $\begin{array}{l}\text { Costs per vial } \\
(\$ \mathrm{US})\end{array}$ & $\begin{array}{l}\text { Total price } \\
\text { (\$US) }\end{array}$ \\
\hline 3 doses of vaccine & 268 & 804 & 7 & 5628 \\
5 doses of vaccine & 107 & 535 & 7 & 3745 \\
1 dose of RIG & 109 & 371 & 65 & 24115 \\
Total & - & - & - & 33488 \\
\hline
\end{tabular}




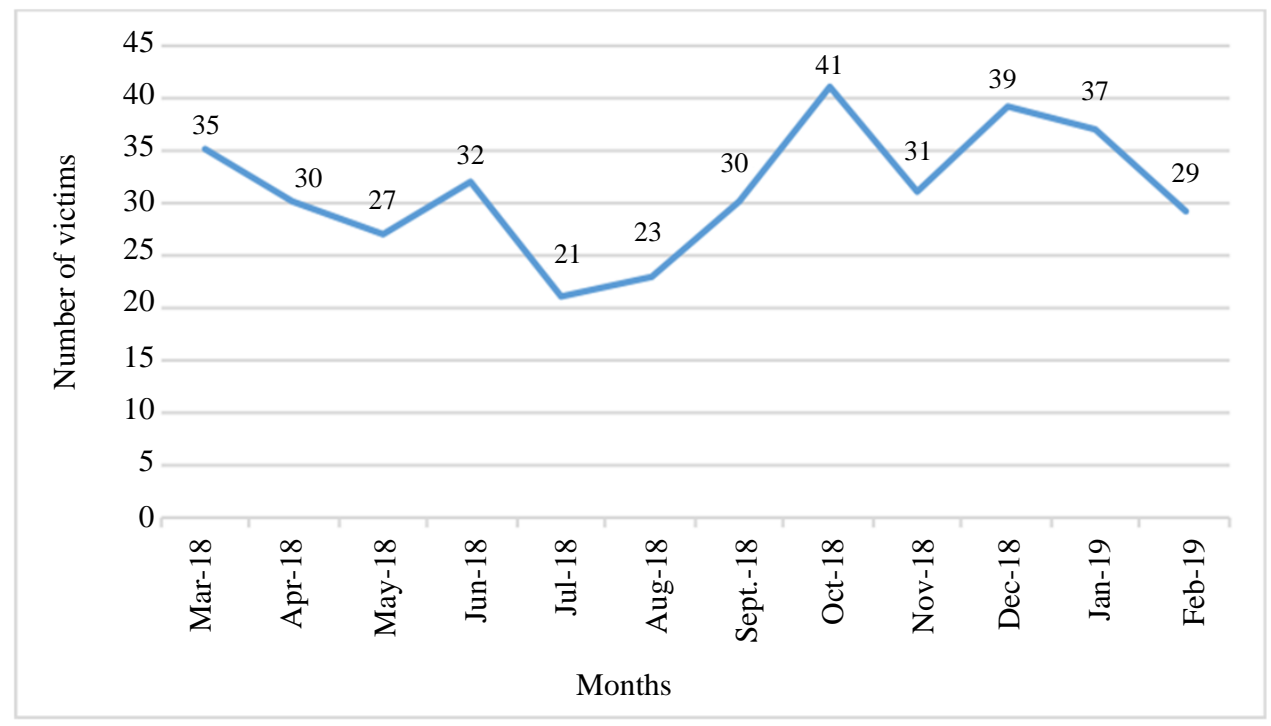

Fig. 1: Frequency of distribution of animal bites cases by month in Larestan county, Fars Province, South of Iran

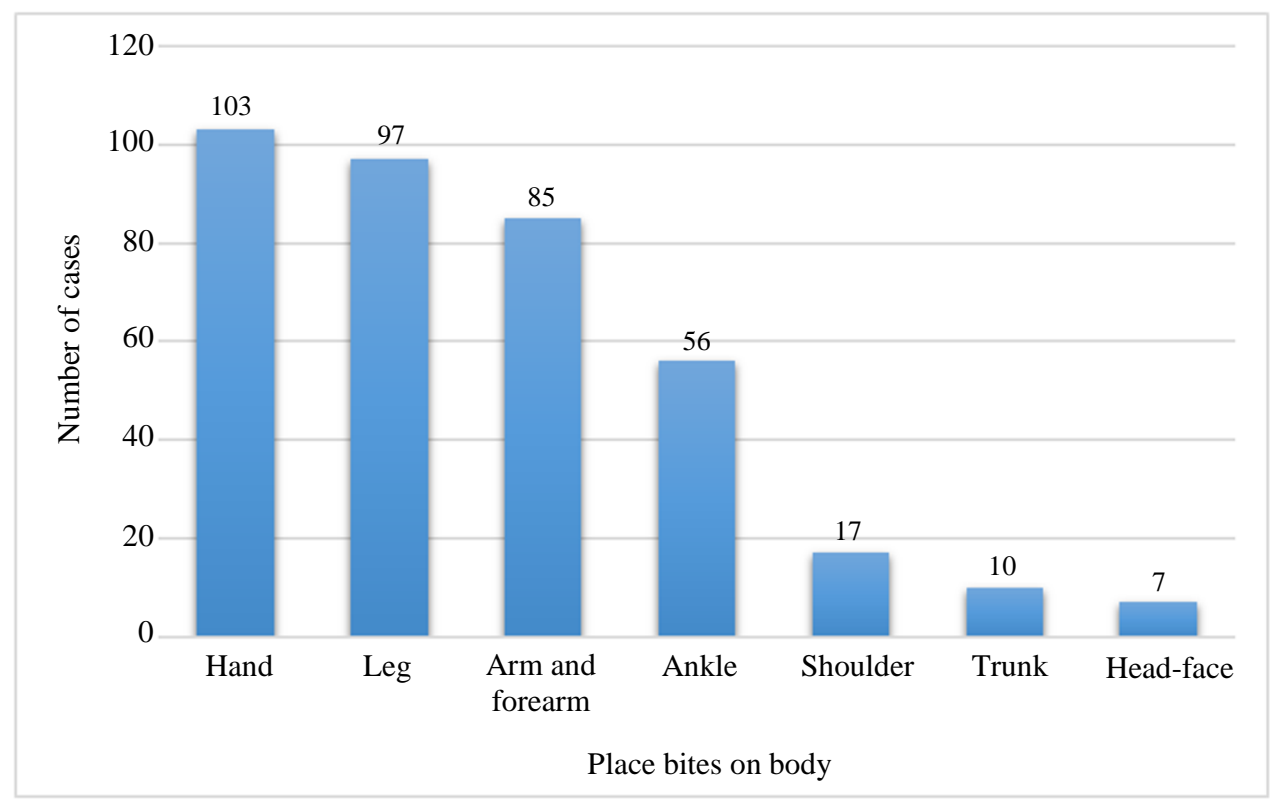

Fig. 2: Frequency of distribution of animal bites cases by bite sites on the body in Larestan county, Fars Province, South of Iran

The cumulative incidence of animal bite during the study period was 170 per 100,000 population. No cases of human rabies were observed in our study.

\section{Cost of Vaccination}

The average direct medical cost of human rabies PET (including the cost of rabies vaccine without considering the costs of keeping, carrying, staff costs and the costs of syringes) was calculated.

The price of each vial of lyophilized rabies vaccine in Iran amount to US\$ 7 and US\$ 65 dollars for each vial of 300 IU RIG. According to the national instructions of
Iran, $300 \mathrm{IU}$ of rabies RIG is needed for each $15 \mathrm{~kg}$ of the victim's weight. The direct costs of total vaccination for all the victims with three and five doses of rabies vaccine, cost of RIG therapy and total direct medical cost of human rabies PET were 9373, 2411 and 33488 dollars, respectively (Table 2).

\section{Discussion}

The results of this study revealed that the incidence rate of animal bites in the county of Larestan was estimated by 170 per 100,000 population in 2018 . 
According to the report by the Center of Disease Control and Prevention in 2018, the overall incidence rate of animal bites had reached 216 per 100,000 population. Naghibi et al. (2014) also reported this incidence rate by 203.4 per 100,000 population in Mazandaran Province, Iran, during 2007-2012. Besides, (Kassiri et al. 2014a) obtained an incidence rate of 282 per 100,000 individuals in the city of Ahvaz, Iran. In the study conducted by (Babazadeh et al., 2016) in the city of Chaldoran in northwestern Iran, the incidence rate of animal bites was reported by 541 per 100,000 population. In another study in the city of Maku, Iran, the incidence rate was reported to be 250 per 100,000 individuals (Shamshirgaran et al., 2017). The reason for the lower incidence rate of animal bites in the county of Larestan compared to the overall average incidence rate in Iran and other regions could be attributable to lack of suitable vegetation and its warm and dry weather conditions in a way that the temperature could reach above $50^{\circ} \mathrm{C}$ in the summer which in turn could lead to an inappropriate habitat for the life of animals, especially wildlife. In this study, the frequency of animal bites in the summer was reported lower than those in other seasons. In addition, residents did not use to keep dogs as pets in urban areas in the county of Larestan and they primarily had dogs as watchdogs or guarding ones in rural areas.

The findings of this study showed that men were more likely to suffer from animal bites than women $(83.7 \%)$. In other investigations, gender distribution of animal bites was reported the same for example (Poorolajal et al., 2015) in the city of Tehran, (Kassiri et al., 2014b) in the city of (Shamshirgaran et al., 2017) in the city of Tehran in Iran illustrated that 84.5, 75.4 and $79.16 \%$ of animal bite cases had occurred in men and they achieved similar results in this respect. In a similar study in the southern of India, the proportion of men was reported by $72.4 \%$ (Taylor et al., 2017) which would be due to occupational exposure outside home and more contacts with risk factors (biting animals). In terms of occupational status in this study, farmers and students were more exposed to animal bites than other groups because of farmers' higher exposure to animals in rural environments. The reason for higher incidence rates of animal bites among students was that they were more likely to play with animals or tease them. In this regard, the findings of this study are consistent with the results of other studies (Kassiri et al., 2014a-b; Babaeeian-Moghaddam et al., 2015).

Considering age groups, most animal bites had been occurred in men and women aged 40-49 years which was not in agreement with the results of other studies in a way that the age group of 10-30 years accounted for the most frequent victims (Babazadeh et al., 2016; (Kassiri et al., 2014a-b; Khazaei et al., 2018). The reason for such inconsistency could be the difference in demographic and sociocultural characteristics of the examined regions in terms of age at work and activity as well as occupational conditions such as agriculture and animal husbandry along with exposure to attacking animals.

In this study, most bites had been caused by dogs which were consistent with the results of other investigations (Kassiri et al., 2014a; Poorolajal et al., 2015; Ghaffari-Fam et al., 2016). This could be owing to the greater coexistence of this animal with humans and its use as a watchdog. Other epidemiologic studies in other regions of the world had also indicated that a high percentage of animal bites had been from dogs (Smith, 2014; Lyu et al., 2016).

Morters et al. (2013) reported in their study that Control measures for canine rabies include vaccination and reducing population density through culling or sterilization. Also (Taylor et al., 2017) reported in their study that Integrating Dog Population Management (DPM) programs into rabies elimination programs could supplement the goal of breaking the rabies transmission cycle with the goal of stabilizing dog populations.

In the present study, most of the bite sites were observed in the hand $(27.46 \%)$ which was in line with the results of other investigations in this field (Amiri et al., 2020; Janatolmakan et al., 2020). However, in a number of studies, the leg was reported as the most injured member (Abedi et al., 2019; Kassiri et al., 2014a; Sharafi et al., 2016) this difference was due the difference in the anatomic categorization in these studies. Moreover, contrary to popular belief that most animal bites were caused by stray animals and given that every year significant costs were spent on the elimination of stray animals in most cases, the results of this study demonstrated that $64 \%$ of the animal bite cases had come from owned attacking animals.

The results of this study indicated that high costs (US\$ 33488) were spent on vaccinating the victims of animal bites against rabies and providing them with immunoglobulin (Table 1). However, this study only shows the costs of rabies vaccines and the immunoglobulin. If a broader viewpoint was taken adding the direct costs such as the material costs (syringe, needles, swabs, antiseptic, etc.) and overhead/operating costs (including staff salaries) and indirect patient costs such as transport costs, income loss and intangible costs like pain and suffering produced by animal bites injury; total costs caused by animal bites would be reported much more.

Accordingly, (Wangdi and Ward, 2012) in their study on costs of human and animal rabies control and prevention in Bhutan in 2012 showed that the total direct cost of rabies and various interventions between 2001 and 2008 was estimated to be \$US 1.03 million. 
The direct cost for the intensified human pet was also estimated to be \$US 0.11 million per year with a cumulative estimated cost of \$US 0.70 million while the cost of mass dog vaccination with at least $70 \%$ coverage was estimated to be approximately \$US 0.21 million at the end of six years.

The limitation of this study is due to its retrospective design in which incomplete records of the victims may cause misclassification or the low quality of recorded data may lead to classification bias.

\section{Conclusion}

The results of this study showed that the main cases of animal bites in the county of Larestan had been caused by dogs and owned animals which could impose a heavy burden on Iran's economy, healthcare system, the community and families. Therefore, conventional and common policies including stray animal elimination needed to be revised in the animal bites and rabies surveillance system and also planning for vaccination of owned animals and their control and containment as well as extensive education for the community on the prevention of animal bites should be considered as priorities for rabies prevention and control plan. Also, due to most bites occurred by dogs, it is recommended to consider vaccination of domestic dogs and they should have a collar during the day.

\section{Acknowledgement}

The authors would like to acknowledge the support of staff who worked in animal bite clinics and treatment centers, Health Deputy of Larestan University of Medical Sciences, Iran

\section{Funding}

This study was conducted using existing data from the primary health care system and did not impose additional costs. There is no external fund to conduct this study.

\section{Authors Contributions}

Vahid Rahmanian: Design of study, proposal of study writing, data gathering, manuscript preparation, literature search and final revision of the study content, final approval of the version the manuscript.

Heshmatollah Shakeri: Organized the study, proposal of study writing, data gathering, manuscript preparation, literature search and final revision of the study.

Abdolreza Sotoodeh Jahrom: Writing, Analysis and interpretation of data, manuscript editing, final revision of the study content, final approval of the version the manuscript.
Masihollah Shakeri: Design of study, Analysis and interpretation of data literature search and final revision of the study content, final approval of the version the manuscript.

Hekmatollah Khoubfekr: Design of study, Analysis and interpretation of data literature search and final revision of the study content, final approval of the version the manuscript.

Iman Hatami: Data gathering, manuscript editing, literature search and final revision of the study content, final approval of the version the manuscript.

\section{Ethical Considerations}

This study was performed in compliance with the Declaration of Helsinki ethical principles for medical research involving human subjects.

\section{References}

Abedi, M., Doosti-Irani, A., Jahanbakhsh, F., \& Sahebkar, A. (2019). Epidemiology of animal bite in Iran during a 20-year period (1993-2013): a metaanalysis. Tropical Medicine and Health, 47(1), 55.

Amiri, S., Maleki, Z., Nikbakht, H. A., Hassanipour, S., Salehiniya, H., Ghayour, A. R., ... \& Ghaem, H. (2020). Epidemiological Patterns of Animal Bites in the Najafabad, Center of Iran (2012-2017). Annals of Global Health, 86(1).

Anyiam, F., Lechenne, M., Mindekem, R., Oussigéré, A., Naissengar, S., Alfaroukh, I. O., ... \& Zinsstag, J. (2017). Cost-estimate and proposal for a development impact bond for canine rabies elimination by mass vaccination in Chad. Acta tropica, 175, 112-120.

Babaeeian-Moghaddam, M., Hashemi-nazari, S. S., \& Khodakarim, S. (2015). Epidemiological study on animal bite cases and its related injury in Quchan district in2013. Irtiqā-yi $\overline{1} \min \overline{1}$ va pīshgīrī az mașdūmiyat/ha (ie, Safety Promotion and Injury Prevention), 3(1), 9-14.

Babazadeh, T., Nikbakhat, H. A., Daemi, A., YeganeKasgari, M., Ghaffari-Fam, S., \& Banaye-Jeddi, M. (2016). Epidemiology of acute animal bite and the direct cost of rabies vaccination. Journal of Acute disease, 5(6), 488-492.

Banyard, A. C., McElhinney, L. M., Johnson, N., \& Fooks, A. R. (2018). Introduction History of rabies control by vaccination. Revue scientifique et technique (International Office of Epizootics), 37(2), 305-322.

Ghaffari-Fam, S., Hosseini, S. R., Daemi, A., Heydari, H., Malekzade, R., Ayubi, E., \& Nikbakht, H. A. (2016). Epidemiological patterns of animal bites in the Babol County, North of Iran. Journal of Acute Disease, 5(2), 126-130. 
Gholami, A., Massoudi, S., Kharazian Moghaddam, M., Ghazi Marashi, M., Marashi, M., Bashar, R., ... \& Shirzadi, M. R. (2017). The role of the gray wolf in rabies transmission in Iran and preliminary assessment of an oral rabies vaccine in this animal. Journal of Medical Microbiology and Infectious Diseases, 5(3), 56-61.

Hamta, A., Saghafipour, A., Hosseinalipour, S. A., \& Rezaei, F. (2019). Forecasting delay times in postexposure prophylaxis to human animal bite injuries in Central Iran: A decision tree analysis. Veterinary world, 12(7), 965.

Janatolmakan, M., Delpak, M., Abdi, A., Mohamadi, S. Andayeshgar, B., \& Khatony, A. (2020). Epidemiological study on animal bite cases referred to Haji Daii health Center in Kermanshah province, Iran during 2013-2017. BMC public health, 20, 1-8.

Kasem, S., Hussein, R., Al-Doweriej, A., Qasim, I., AbuObeida, A., Almulhim, I., ... \& Al-Mujalli, D. (2019). Rabies among animals in Saudi Arabia. Journal of infection and public health, 12(3), 445-447.

Kassiri, H., Kassiri, A., Mosavi, R., Jashireh, A., \& Lotfi, M. (2014a). Prevalence rate and epidemiological determinants of animal bite in Ahvaz County, Khuzestan Province, Southwestern Iran. Journal of Acute Disease, 3(1), 51-55.

Kassiri, H., Kassiri, A., Lotfi, M., Shahkarami, B., \& Hosseini, S. S. (2014b). Animal bite incidence in the County of Shush, Iran. Journal of Acute Disease, 3(1), 26-30.

Khazaei, S., Karami, M., Veisani, Y., Solgi, M., \& Goodarzi, S. (2018). Epidemiology of animal bites and associated factors with delay in post-exposure prophylaxis; a cross-sectional study. Bulletin of Emergency \& Trauma, 6(3), 239.

Le, K. R., Kotze, J., \& Perrett, K. (2018). Elimination of dog-mediated human rabies: the burden of human rabies in Africa. Revue scientifique et technique (International Office of Epizootics), 37(2), 607-615.

Lyu, C., Jewell, M. P., Piron, J., Ehnert, K., Beeler, E., Swanson, A., ... \& Kuo, T. (2016). Burden of bites by dogs and other animals in Los Angeles County, California, 2009-2011. Public Health Reports, 131(6), 800-808.

Mbilo, C., Kabongo, J. B., Pyana, P. P., Nlonda, L., Nzita, R. W., Luntadila, B., ... \& Zinsstag, J. (2019). Dog Ecology, Bite Incidence and Disease Awareness: A Cross-Sectional Survey among a Rabies-Affected Community in the Democratic Republic of the Congo. Vaccines, 7(3), 98.

Morters, M. K., Restif, O., Hampson, K., Cleaveland, S., Wood, J. L., \& Conlan, A. J. (2013). Evidence-based control of canine rabies: a critical review of population density reduction. Journal of animal ecology, 82(1), 6-14.
Naghibi, S. A., YazdaniCharati, J., \& Shojaie, J. (2014). Epidemiological characteristic of animalbite cases in Mazandaran, 2004-2011. Journal of Mazandaran University of Medical Sciences, 24(117), 218-224.

Poorolajal, J., Babaee, I., Yoosefi, R., \& Farnoosh, F. (2015). Animal bite and deficiencies in rabies postexposure prophylaxis in Tehran, Iran. Archives of Iranian medicine, 18(12), 0-0.

Shamshirgaran, S. M., Barzkar, H., Ghaffari-Fam, S., Kosha, A., Sarbakhsh, P., \& Ghasemzadeh, P. (2017). Epidemiological characteristics and trends in the incidence of animal bites in Maku County, Islamic Republic of Iran, 2003-2012. Eastern Mediterranean Health Journal, 23(7), 507.

Sharafi, A. C., Tarrahi, M. J., Saki, M., Sharafi, M. M., Nasiri, E., \& Mokhayeri, H. (2016). Epidemiological Study of Animal Bites and Rabies in Lorestan Province in West of Iran During 20042014 for Preventive Purposes. International journal of preventive medicine, 7 .

Shwiff, S. A., Elser, J. L., Ernst, K. H., Shwiff, S. S., \& Anderson, A. M. (2018). Cost-benefit analysis of controlling rabies: placing economics at the heart of rabies control to focus political will.

Smith, S. L. (2014). The emergence, growth and decline of political priority for newborn survival in Bolivia. Health policy and planning, 29(8), 951-959.

Taylor, L. H., Wallace, R. M., Balaram, D., Lindenmayer, J. M., Eckery, D. C., Mutonono-Watkiss, B., ... \& Nel, L. H. (2017). The role of dog population management in rabies elimination-a review of current approaches and future opportunities. Frontiers in Veterinary Science, 4, 109.

Tiembré, I., Broban, A., Bénié, J., Tetchi, M., Druelles, S., \& L'Azou, M. (2018). Human rabies in Côte d'Ivoire 2014-2016: Results following reinforcements to rabies surveillance. PLoS neglected tropical diseases, 12(9), e0006649.

Wangdi, K., \& Ward, M. P. (2012). Human and animal rabies prevention and control cost in Bhutan, 20012008: the cost-benefit of dog rabies elimination. Vaccine, 31(1), 260-270. 